Open Access

\title{
The 2017 national survey of online learning in Canadian post-secondary education: methodology and results
}

Tony Bates

Correspondence: tony.bates@ubc.ca Distinguished Visiting Professor, The G. Raymond Chang School of Continuing Education, Ryerson University, Toronto, Ontario, Canada

\begin{abstract}
Canada has a long history of online and distance education, but until 2017 there had been no comprehensive national data on online enrolments in both the university and college sectors. However, in 2017 a team of independent Canadian researchers, working in collaboration with the Babson Survey Research Group and WCET in the USA, raised the funding and conducted a national survey of online learning in all public post-secondary institutions in Canada. The results from the survey are presented and discussed, as well as plans for further studies in the future.
\end{abstract}

Keywords: Online learning, Distance education, Canada, Survey methodology, Post-secondary education

\section{Introduction}

As online learning becomes more and more prevalent in post-secondary education, it becomes particularly important to be able to track its development.

Canada has a highly devolved post-secondary education system, with individual provinces responsible for funding universities and colleges. Moreover the institutions themselves have a good deal of autonomy. There is no national agency responsible for post-secondary education in Canada, and therefore no obvious sources of funding for surveying and tracking developments in post-secondary education. Statistics Canada does track overall enrolments and institutional and student financing. However it rarely conducts surveys of specific activities within the post-secondary sector.

There have been several studies that have provided data on online enrolments, such as the Canadian Virtual Universities annual enrolment data, studies conducted by the Ontario and Québec provincial governments, and a report by Contact North (2015) which stated: 'Our best guess is that, in any semester, Canada has over 1.3 million online course registrations'. These reports are discussed in more detail in the Conclusion (p.14). However, while individually useful, they provide incomplete or unreliable data for the whole system.

Therefore it was necessary to develop a specific study to track the development of online and distance learning in Canadian post-secondary education. This article looks not just at the results but the methodological issues involved in conducting such a study.

(c) The Author(s). 2018 Open Access This article is distributed under the terms of the Creative Commons Attribution 4.0 International License (http://creativecommons.org/licenses/by/4.0/), which permits unrestricted use, distribution, and reproduction in any medium, provided you give appropriate credit to the original author(s) and the source, provide a link to the Creative Commons license, and indicate if changes were made. 


\section{Origin of the project \\ Rationale}

In the USA, the annual surveys of the Babson Survey Research Group (BSRG) between 2002 and 2011 recorded rapid growth in online learning and identified policies and directions being taken by U.S. universities and colleges (see for instance, Allen \& Seaman, 2013). In 2012, the United States Department of Education started collecting similar data through its IPEDS (Integrated Postsecondary Education System Data) survey. When IPEDS began collecting distance learning enrolments in the fall of 2012, BSRG switched to reporting the Department's statistics. For the most recent IPEDS data collection, BSRG analyzed the data with WCET (WICHE Cooperative for Educational Technologies) and the e-Literate blog under the partnership name of the Digital Learning Compass (Allen \& Seaman, 2017; Seaman, Allen, \& Seaman, 2018).

Institutional planners, state higher education officials and the media in the United States have made heavy use of the annual survey reports. These reports have had a large impact on both public policy at federal and state levels, and on institutional policies and practices regarding online learning.

However, no such similar data about online learning in Canadian institutions were being collected. Without such data, it is difficult for university and college leaders to track their comparative progress in online learning, the likely future demand, the use of open educational resources, the impact of online learning on teaching, or what strategies are succeeding or failing.

\section{Building a research team}

In early 2016, Jeff Seaman of the Babson Survey Research Group and Russell Poulin of WCET initially approached Tricia Donovan, the Director of eCampus Alberta, with the proposal for a Canadian survey. Tony Bates, a Research Associate for Contact North and a Distinguished Visiting Professor in Continuing Studies at Ryerson University was then approached. He had been strongly advocating for such a Canadian survey, and agreed to take leadership of the project. Jeff Seaman provided services for questionnaire administration, data processing and analysis and Russell Poulin advised on analysis and differences with the USA. Tricia Donovan helped with liaison with various organizations whose support was essential for the success of the project.

It was recognized from the start that strong and direct liaison with individual universities and colleges would be critical for the success of the survey. Also it was essential to ensure the participation of francophone as well as anglophone institutions. As a result three consultants were brought on board:

- Brian Desbiens, a former college president from Ontario, to liaise with the anglophone college sector;

- Denis Mayer, a former associate vice president, student affairs, Laurentian University (a bilingual university in Ontario) to liaise with the francophone universities, colleges and CEGEPs;

- Ross Paul, a former Canadian university president, to liaise with the anglophone university sector. 
These three consultants, with their extensive experience, knowledge and network of contacts within their sector, were critical elements of the study. Later in the study, Eric Martel of Université Laval joined the team to strengthen liaison with institutions within the province of Québec.

\section{Funding}

The survey started as an idea without any immediate institutional support, no national or provincial sponsors, and with no commercial sponsorship. Money for the project had to be raised in three stages.

For the first stage, the various provincial government organizations mandated to support online learning were approached:

- Contact North (Ontario),

- BCcampus (British Columbia),

- eCampus Alberta,

- Campus Manitoba, and

- eCampus Ontario.

Each contributed $\$ 5000$ to $\$ 10,000$ towards the first stage of the project $(\$ 45,000$ in total). This stage focused on winning widespread support for the project within the Canadian post-secondary education sector, developing the initial design and piloting of the questionnaire, and the development of a database on every public Canadian post-secondary educational institution, including identification of appropriate contact people in the institutions.

The second and most expensive stage of the project was the piloting and administration of the questionnaire. This involved sending invitations to participate to each of 203 institutions, and follow-up contacts to ensure a high response rate.

This stage was made possible by a grant of $\$ 80,000$ from eCampus Ontario's Research and Development fund to Ryerson University, where Tony Bates was a distinguished visiting professor.

The third stage of the project involved analysis of the data, writing up of the report and its dissemination, including a special francophone report and translation. This was funded partly through the eCampus Ontario grant and grants of $\$ 20,000$ each from Pearson Canada and D2L. Altogether a total of $\$ 165,000$ was raised for the project. This proved to be a very tight budget, with nothing left for future developments, but it was sufficient for meeting all the immediate goals of the project.

\section{Gaining recognition and participation}

Post-secondary institutions in Canada receive a great many requests from their governments and other agencies for student and financial data. There is a cost to the institutions in collecting and organising such data.

Without a direct provincial or national sponsor for the project, the participation of institutions was absolutely dependent on their willingness to participate. To obtain this commitment, the team approached a number of organizations to which the post-secondary institutions belonged. Although these organizations could not make 
their members participate, without their endorsement or support then the participation rate would likely be very low. With the support of these organizations, institutions would be more likely to participate. Some formally endorsed the work and actively promoted it. Others, in one form or another, played an important supportive role in ensuring that the survey was well received by the institutions.

\section{Methodology and response rate}

\section{The Canadian post-secondary education system}

To understand the methodological approach, a brief explanation of the Canadian post-secondary education system is necessary (Fig. 1).

Education is constitutionally the responsibility of the ten provinces and the three territories. Thus there is no national higher education system in Canada. There is no Federal Ministry or Department with responsibility for post-secondary education, although the federal government does provide student aid and tax breaks for students and their parents, and funding for research and innovation. The federal government is largely responsible for funding higher education opportunities for aboriginal learners, although aboriginal students who go on to post-secondary education in most cases attend a provincially funded institution.

There are four main categories or types of public post-secondary institution in Canada:

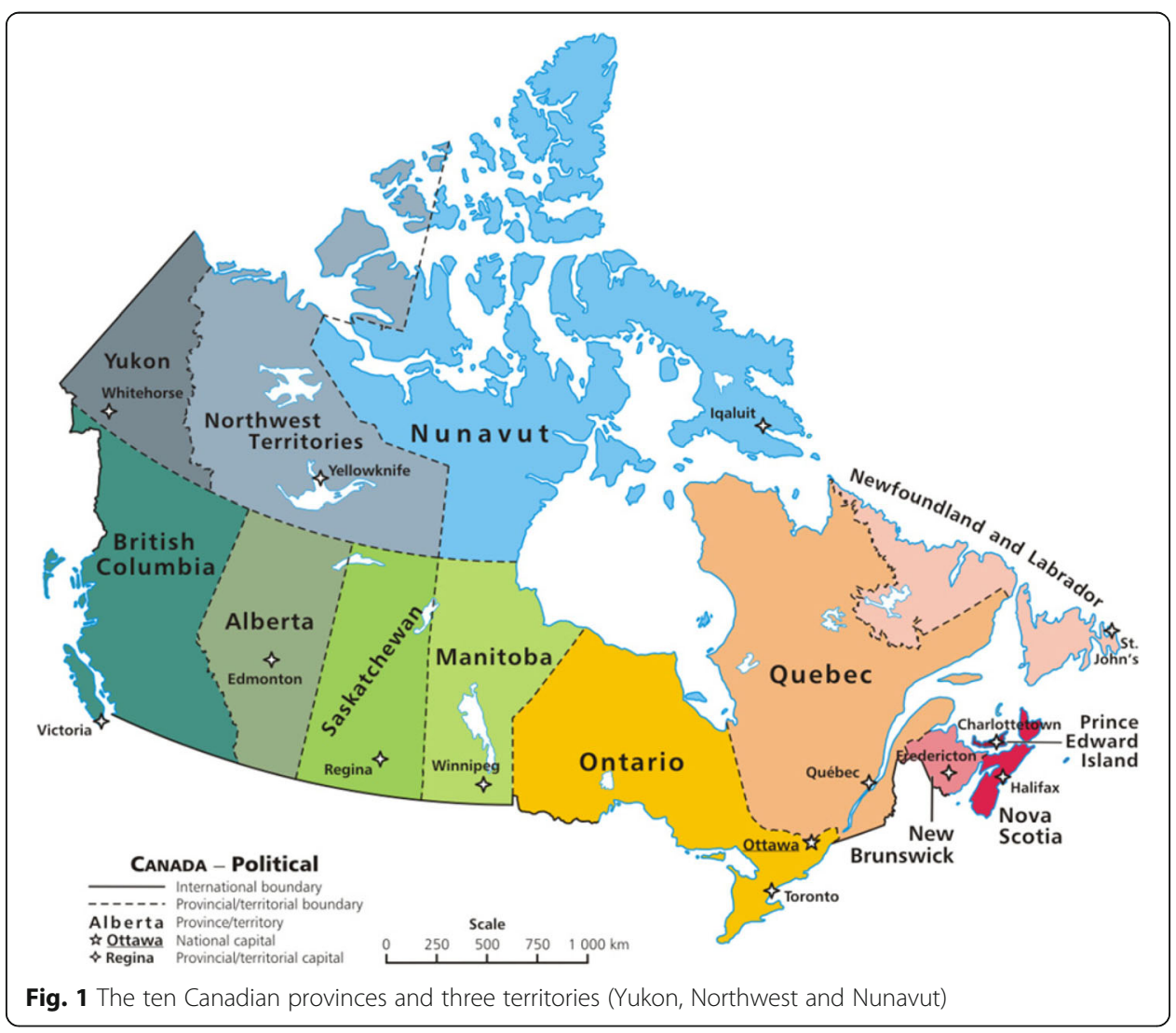


- universities,

- one- and two-year professional and vocational colleges,

- polytechnics and institutes of technology,

- CEGEPs (general and vocational colleges) in Québec.

Some explanation of CEGEPs (Collèges d'Enseignement Général et Professionnel) is needed, as they are unique to the province of Québec. CEGEPS provide a step between secondary high school and university. The vast majority of Quebec students start CEGEP at age 17. Depending on their educational objectives, some will then continue on to university, while others will enter the workforce with strong practical skills and knowledge following 3 years of technical studies. Students in CEGEPs can cover what in other parts of Canada would be the first year of university-type education. In the rest of Canada, students leaving high school and entering post-secondary education go either to a four-year university or a two- to three-year college or straight into the workforce. Although in the main cities there are larger CEGEPs, the majority of CEGEPs are small to medium sized (70\% have fewer than 4000 students). Some CEGEPs have responsibility for very large but sparsely populated areas.

\section{The scope of the project}

To manage the scope of the project, the study focused solely on public, provincially funded post-secondary institutions. Almost all universities are provincially funded and there are very few private, for-profit universities in Canada. There are private, mainly religious-based, universities with provincial legal status but they are quite small, and few in number. There are numerous private, for-profit vocational colleges, but still the majority of two-year college students in Canada attend provincially funded institutions.

The other important factor is language. There are 43 francophone and five anglophone CEGEPs in Québec as well as a provincially funded francophone professional college. The majority of universities in Québec are also francophone, but there are also three anglophone universities. In the rest of Canada, the majority of post-secondary institutions are anglophone, but in most provinces there is at least one francophone institution, or a separate francophone program in a bilingual university.

To manage the scope of the project an early decision was made to focus only on online and distance courses and programs that lead to institutional credits such as degrees or diplomas, although the importance of online learning and distance education for continuing education non-credit students was recognized. However, including non-credit courses and programs would have complicated the data collection, especially as this was the first year of the project. It is desirable in future years also to track continuing education students and their use of online and distance education.

A number of aboriginal communities/First Nations manage their own post-secondary colleges. Lastly there are at least two Federal post-secondary institutions, the Royal Military College/Collège Militaire Royal, and the Canadian Coast Guard College. Both the federal and indigenous institutions are unique in their organization and goals and operate relatively independently of the provincial systems, and for the initial survey, they were excluded. 
Thus in the first year of the project, the focus was exclusively on provincially funded and accredited post-secondary educational institutions, which still represent by far the majority of post-secondary institutions in Canada, and on courses and programs leading to recognised institutional degrees and diplomas.

\section{Creating a database of institutions}

One challenge the project faced was the lack of a commonly used, publicly accessible database of all Canadian public post-secondary educational institutions. Statistics Canada (StatCan) collects and publishes aggregate national data on topics such as the funding of post-secondary education, overall student enrolments and student workforce participation, but there was not available a single, publicly available source that listed all public post-secondary institutions in Canada.

Universities Canada, and Colleges and Institutes Canada (CICAN), both publish a list of their members, but with regard to the universities, a number of members are colleges or affiliates of a larger institution that awards their credentials. Although the membership of Universities Canada was used as a major source to identify Canadian universities, the affiliated institutions and religious-based colleges were included within their parent university in order to avoid duplicating data collection. Also not all members of Universities Canada are provincially accredited. Furthermore not all public post-secondary colleges are members of CICAN. Some universities are also members of CICAN as well as Universities Canada.

Provincial government web sites were searched to identify provincially recognized colleges and universities (although not every province provides such a list on their web site).

In the province of Québec, the web-sites of Fédération des CÉGEPs du Québec and le Réseau des universités du Québec were searched. In addition to the 48 campus-based CEGEPs, there is a central distance education service for the CEGEP system, Cégep à distance, so Cégep à distance was included, plus a provincially funded francophone professional/vocational college in Québec, resulting in 50 CEGEPs in total.

Also in Québec, Université Téluq is a publicly funded and accredited autonomous distance education university that operates in parallel with the other universities in Québec. However, unlike Cégep à distance for the CEGEPs, Université Téluq does not offer programs on behalf of the other universities.

The result was a population base of 203 institutions for the survey:

- 72 universities (35\%),

- 81 colleges outside Québec (40\%),

- 50 CEGEPs/colleges within Québec (25\%).

Of the 203 institutions, 70 (34\%) were either francophone institutions or were bi-lingual institutions with a separate francophone program.

Then for each of the institutions, it was necessary to identify the appropriate contact person or people. In most cases, the initial approach was to the Vice-President Academic or VP Education. 
Building the initial database of institutions and identifying appropriate contacts was the most time-consuming and costly part of the project.

\section{Identifying student numbers}

In order to provide cross-validation of data collected through the survey, and also to take account of the size of each institution in the data analysis, a number of sources were used to find independent data about the number of students studying for institutional credit in each institution.

The most reliable source for credit-based student enrolment numbers was the official student headcount numbers for each institution made available on provincial government web sites. These figures though ranged from data collected in 2011 through to 2016. Provinces also differed in how they counted student enrolments, some using headcounts (irrespective of the number of course enrolments), some excluded part-time students, and some calculated full-time equivalents using different fractions for part-time students.

This was an important check for the survey data, as some institutions reported total online course enrolment numbers, which are much larger than the actual online student headcount. The lack of consistency in what counts as an online student though was never completely resolved throughout the project.

Nevertheless in general provincial government web sites provided the most consistent source of comparative data on the size of institutions. In the few provinces or territories where this data was not available from Ministry web sites, published institutional annual reports or government audits of student headcounts for individual institutions were analyzed.

For the 2017 survey we used Statistics Canada figures for Canadian post-secondary student enrolments for the fall of the 2014/2015 academic year [http://www.statcan.gc.ca/tables-tableaux/sum-som/101/cst01/educ71a-eng.htm], which were the most recent available at the time. Their enrolment numbers were based on program counts and not student counts. If a student is enrolled in more than one program as of the snapshot date, then all of their programs are included in the count.

Comparing the online survey population base with Statistics Canada's, the following differences in student enrolments were found (Table 1):

Without knowing more about the basis on which Statistics Canada built its data, we cannot explain the difference between the two populations sets, but the differences are relatively small, except for CEGEPs. For CEGEPs the survey used data for student places directly funded by the Québec government and as a result may have missed out-of-province

Table 1 Comparison of Statistics Canada student enrolment numbers, and student headcount totals from institutions in the survey population base

\begin{tabular}{lrrrr}
\hline & Universities & Colleges & CEGEPs & Total \\
\hline StatCan & $1,306,110$ & 526,989 & 221,844 & $2,054,943$ \\
Our project & $1,239,801$ & 512,785 & 162,762 & $1,915,348$ \\
Difference & 66,309 & 14,204 & 59,082 & 139,595 \\
\% difference & $5 \%$ & $3 \%$ & $27 \%$ & $7 \%$ \\
\hline
\end{tabular}


and international students, and students funded from other sources. Overall, though, the population base for the project appears to represent a very large proportion (93\%) of students studying for institutional credit at Canadian public post-secondary institutions.

\section{Designing the questionnaire}

The questionnaire design was initially based on the design of the Babson Surveys, but was heavily modified to meet the Canadian context. However, for comparison purposes several key questions remained common to both surveys.

There are in fact several versions of the Canadian questionnaire, for:

- anglophone universities,

- francophone universities,

- anglophone colleges,

- francophone colleges (outside Québec),

- CEGEPs (within Québec).

The questionnaire was piloted in six universities and six colleges distributed across the country in both francophone and anglophone institutions. Their feedback strongly influenced the final design. Also extensive efforts were made to consult with professional associations, university and college organizations, and senior administrators within different types of post-secondary institution before finalizing the questionnaire.

For the universities, an invitation to participate was sent initially to the Provost/Vice President, Academic. For those colleges and some universities that were members of CICAN, the invitation to participate was sent by CICAN, using CICAN's e-mail list of member contacts, while in some cases, the invitation went to Direction des études in the francophone institutions.

The questionnaire itself was online and was accessed using a link unique for each participant institution. Members of the project team actively followed up with institutions to encourage them to participate. The project was also promoted through post-secondary educational networks or provincial organizations. The invitations went out in early May and the final cut-off date for the full questionnaire was June 30, 2017.

At this point, for those institutions that had not responded, an invitation was sent to the Vice-President Academic, and their equivalent in colleges and CEGEPs, to complete a shorter questionnaire that excluded questions on student enrolments.

\section{Definitions}

There is no general agreement on definitions in this field. Furthermore online learning is a dynamic, fast-changing area of education. However, for a project of this kind, it is essential that all institutions as far as possible use the same terminology and understanding when completing the questionnaire.

Thus, for the purposes of this project, the following definitions were used, which were included in the introduction to the questionnaire:

Distance education courses. Distance education courses are those where no classes are held on campus - all instruction is conducted at a distance. Distance education courses 
may use a variety of delivery methods, such as print-based, video/audio-conferencing, as well as internet-based.

Online courses. A form of distance education where the primary delivery mechanism is via the internet. These could be delivered synchronously or asynchronously. All instruction is conducted at a distance.

Online program. A for-credit program that can be completed entirely by taking online courses, without the need for any on-campus classes. It could be delivered synchronously or asynchronously.

Blended/hybrid courses. These are courses are designed to combine both online and face-to-face teaching in any combination. For the purposes of this questionnaire, we are interested in those courses where some, but not all, of the face-to-face teaching has been replaced by online study.

Credit courses. These are courses that lead to institutional credits (degrees, diplomas, etc.). In other words please exclude non-credit programming for the purpose of this survey, except where specifically indicated. Include information on all credit online courses, whether they are managed by a central service or by individual departments or by Continuing Studies.

MOOCs. These are massive, open, online courses. The key features are:

- No fee (except possibly for an end of course certificate),

- The courses are open to anyone: there is no requirement for prior academic qualifications in order to take the course,

- The courses are not for credit.

There was a separate section in the questionnaire about MOOCs.

\section{Response rate}

Table 2 below shows that the overall institutional response rate was $69 \%$ of the 203 institutions in the population base. Responses were higher from universities and lower for CEGEPs.

The response rate tended to be lower from the smaller institutions. From Table 3 below it can be seen that 15 out of the 19 colleges with more than 10,000 students responded (79\%), compared to 59\% for those colleges with fewer than 2000 students.

Larger universities were also more likely to respond. For the 29 universities with fewer than 7500 students, the response rate was $62 \%$, but $86 \%$ for the 43 with more than 7500 students. Nevertheless, the response rate for all size ranges of institution was $50 \%$ or more, including for small colleges and CEGEPs.

Table 2 Response rate by type of institution

\begin{tabular}{lrrrrrrrr}
\hline & \multicolumn{2}{c}{ Full questionnaire } & & Short questionnaire & \multicolumn{3}{c}{ Total response } \\
\cline { 2 - 5 } & Resp. & Pop. & $\%$ & Resp. & Resp. & Pop. & $\%$ \\
\hline Universities & 49 & 72 & 68 & 7 & 56 & 72 & 77 \\
Colleges (except Quebec) & 54 & 81 & 67 & 1 & 55 & 81 & 68 \\
CEGEPs (Québec) & 25 & 50 & 50 & 4 & 29 & 50 & 58 \\
Total & 128 & 203 & 63 & 12 & 140 & 203 & 69 \\
\hline
\end{tabular}

Resp. $=$ responding institutions; Pop. $=$ all institutions in population base 
Table 3 Response rate by size range of colleges (including CEGEPs)

\begin{tabular}{lccc}
\hline & & Total response & \\
& Resp. & Pop. & $\%$ \\
\hline$<2000$ & 27 & 46 & 59 \\
$2000-9999$ & 42 & 66 & 64 \\
$10,000+$ & 15 & 19 & 79 \\
Total & 84 & 131 & 64 \\
\hline
\end{tabular}

Since there was a higher response rate from the larger institutions, the questionnaire responders represent institutions with $78 \%$ of the student population base, as can be seen in Table 4.

Responses from Quebec as a whole were slightly lower than average $(60 \%$ for all Quebec institutions) compared with that for the universities and colleges outside Québec (72\%). The response to the national survey may have been influenced by a similar request for extensive enrolment data at the same time by the Québec Ministère de l'Éducation et de l'Enseignement Supérieur (Table 5).

Overall, especially considering that this was a voluntary questionnaire, the responses provide an excellent, representative sample of colleges and universities across all provinces, and across all sizes of institution, representing $69 \%$ of all institutions and $78 \%$ of all students studying for institutional credit at Canadian public post-secondary institutions.

\section{Main results}

\section{Declaration: Availability of data and material}

There is a web site for the survey [https://onlinelearningsurveycanada.ca/] that contains copies of the project reports, including the main public report (Bates et al., 2017), a full technical report, and sub-reports. The web site also contains all the tables from the survey. There is also a francophone web site for the survey [https://formationenlignecanada.ca/] that mirrors the anglophone site, including translations of the reports.

Copies of the questionnaires and the source data from the questionnaires, including open-ended comments, are being lodged with the Ontario College Application Service (OCAS) [https://www.ocas.ca/what-we-do/ontariocolleges] and will be available on request to bona fide researchers.

\section{Extent of activity}

Online learning and distance education were clearly alive and well in Canada in 2017, with a strong annual growth rate in online enrolments and most institutions playing an

Table 4 Student headcounts for institutions responding compared to overall student headcounts

\begin{tabular}{lrrrrrr}
\hline & \multicolumn{3}{c}{ Questionnaire responders } & & \multicolumn{2}{c}{ Student population } \\
\cline { 2 - 4 } Questionnaire & \multicolumn{1}{c}{ Full } & Short & Total & & No. & $\%$ \\
\hline Universities & 916,544 & 104,978 & $1,021,522$ & & $1,239,801$ & $82 \%$ \\
Colleges & 372,565 & 167 & 372,732 & & 512,785 & $73 \%$ \\
CEGEPs & 80,063 & 12,518 & 92,581 & & 162,762 & $57 \%$ \\
Total & $1,369,172$ & 117,663 & $1,486,835$ & & $1,915,348$ & $78 \%$ \\
\hline
\end{tabular}


Table 5 Response rate by province

\begin{tabular}{|c|c|c|c|c|c|c|c|c|c|c|}
\hline \multirow[b]{2}{*}{ Questionnaire } & \multicolumn{4}{|c|}{ Universities } & \multicolumn{4}{|c|}{ Colleges/CEGEPs } & \multicolumn{2}{|c|}{ Total } \\
\hline & $\overline{\text { Full }}$ & Short & Both & All inst. & Full & Short & Both & All inst. & Resp. & All inst. \\
\hline Alberta & 6 & 0 & 6 & 6 & 10 & 0 & 10 & 14 & 16 & 20 \\
\hline British Columbia & 9 & 1 & 10 & 11 & 9 & 0 & 9 & 15 & 19 & 26 \\
\hline Manitoba & 3 & 0 & 3 & 4 & 3 & 0 & 3 & 4 & 6 & 8 \\
\hline N. Brunswick & 2 & 0 & 2 & 4 & 1 & 0 & 1 & 4 & 3 & 8 \\
\hline Newfoundland & 1 & 0 & 1 & 1 & 1 & 0 & 1 & 1 & 2 & 2 \\
\hline NW Territories & 0 & 0 & 0 & 0 & 1 & 0 & 1 & 2 & 1 & 2 \\
\hline Nova Scotia & 5 & 0 & 5 & 8 & 1 & 0 & 1 & 1 & 6 & 9 \\
\hline Nunavut & 0 & 0 & 0 & 0 & 0 & 0 & 0 & 1 & 0 & 1 \\
\hline Ontario & 15 & 3 & 18 & 20 & 21 & 0 & 21 & 26 & 39 & 46 \\
\hline PEI & 0 & 0 & 0 & 1 & 1 & 1 & 2 & 2 & 2 & 3 \\
\hline Quebec & 7 & 3 & 10 & 15 & 25 & 4 & 29 & 50 & 39 & 65 \\
\hline Saskatchewan & 1 & 0 & 1 & 2 & 5 & 0 & 5 & 10 & 6 & 12 \\
\hline Yukon & 0 & 0 & 0 & & 1 & 0 & 1 & 1 & 1 & 1 \\
\hline Total & 49 & 7 & 56 & 72 & 79 & 5 & 84 & 131 & 140 & 203 \\
\hline
\end{tabular}

active role in offering fully online and hybrid learning. Nearly all Canadian universities and colleges outside Québec offer distance education courses for credit.

Canada appears to be a relatively mature market for online learning. Many institutions had been offering online learning for 15 years or more.

Over the period 2011-2016, the number of institutions offering online courses has increased by $11 \%$, a growth rate in the number of institutions moving into online education of around $2 \%$ per annum. In the last few years, even the smaller institutions have moved to offer online learning courses and programs. However, with most institutions now offering online courses, there is little further room for growth in terms of institutions.

Nevertheless, fully online student enrolments have been growing rapidly over the last 5 years, with online course enrolments increasing by approximately $10 \%$ per annum in universities and 15\% in colleges outside Québec.

In Québec, there is a central service for distance education for the CEGEPs, Cégep à distance, but nevertheless half of the responding CEGEPs offered their own distance education courses, although the CEGEP system in Quebec seems to be the least developed in terms of online student enrolments and growth rate. CEGEPs have seen a slight decline (3\%) in online learning since 2011, where activity seems to be slowly transitioning from a central service (Cégep à distance) to individual CEGEPs.

Online course enrolments constituted approximately $16 \%$ of all course enrolments in Canadian universities in 2015, and probably $12 \%$ in colleges outside Québec, although this is an estimate based on several other studies as well as this one (see discussion in the Conclusion (p.14). Obtaining accurate and reliable online student and course enrolment figures from the institutions was a major challenge for this project.

Online courses can be found in every subject area, with online courses in business, education and health (including nursing) being the most frequently offered. Similarly fully online programs are offered in most subject areas in all types of public post-secondary institutions in Canada. 
Just under half of the responding institutions reported that in up to $10 \%$ of their courses, some of the face-to-face teaching has been replaced by online study, and in about a quarter of the institutions, more than $10 \%$ of the teaching was in this format. It was reported that such blended/hybrid learning is resulting in innovative campus-based teaching. Thus although blended and hybrid learning are found in a relatively high proportion of Canadian post-secondary institutions, the penetration of this kind of teaching in individual institutions is growing but is still low relative to fully online learning.

\section{The use of technology in online learning}

All but two of the institutions that responded to the questionnaire used the Internet as the main way to deliver distance courses. Nearly all institutions used a learning management system for online courses but this was often supplemented with other technologies, especially web conferencing and print.

In about a quarter of the institutions, technologies for synchronous delivery, in the form of interactive lectures or webinars, were used, and print is also used to support online learning in a similar number of institutions.

New, low-cost, easy to use technologies such as social media and mobile apps are providing both instructors and students with new ways of teaching and learning. There appears to be a great deal of experimentation going on: or rather a large number of institutions appear to have at least some innovative projects using technology for teaching.

There is relatively limited use of open educational resources (OER) and open textbooks at the moment. Even more striking though was how few references there were in the questionnaire responses to adaptive learning, artificial intelligence, learning analytics and competency-based learning. It seems that these technologies or approaches have yet to prove their worth to Canadian instructors.

\section{MOOCs}

There is no MOOC mania in Canada. Less than $20 \%$ of responding institutions offered MOOCs in the previous 12 months. In most institutions, MOOCs are being cautiously assessed, and used only where they are perceived to add value to standard programming.

\section{Institutional polices for online learning}

Most Canadian post-secondary institutions see online learning as very or extremely important for their future plans and this is true in all sectors and provinces.

Most institutions either have a strategy or plan for online learning or are developing one. A substantial proportion of institutions are moving to expand fully online and hybrid teaching.

\section{Benefits and challenges of online learning for institutions}

The major benefit of online learning perceived by responders was that it results in greater access and more flexibility for students, although almost three-quarters of those responding also saw online learning as a means to increase enrolments. This was 
particularly true for institutions in the Atlantic provinces which are suffering an overall decline in population.

In almost two thirds of the institutions, innovative teaching was perceived as one of the benefits of online learning. This was particularly true for very large institutions (more than 30,000 students). In fact, a range of pedagogical benefits was listed by a significant number of responders.

Most institutions reported that lack of adequate resources was a major barrier to online learning. Nearly half the institutions identified lack of specialist learning technology support staff as a barrier. Lack of resources and specialist staff were particular problems for very small institutions.

About two-thirds of the institutions identified lack of training, and resistance from instructors, as the main barriers or challenges. Faculty resistance was highest in Québec, especially in the CEGEPs.

\section{Inter-provincial differences}

The survey results provide strong evidence that the growth of online learning is driven as much if not more by government policies and strategies as by institutional initiative. Basically, money talks.

Just over a third of the institutions identified a lack of support from government as a challenge. The lowest response to this was from institutions in Ontario (16\%) and the highest in Québec (62\%). CEGEPS also identified lack of government support at a much higher level than colleges outside Québec (57\% compared to 29\%). The recent rapid growth in online enrolments in Ontario coincided with the Ontario government's funding of eCampus Ontario, whereas in British Columbia, the initial burst of online course development in the early 2000s has slowed as direct government funding for online course development has been switched to open textbooks and open educational resources.

Québec on the other hand is (as usual) more complex and interesting. The regular universities appear to be moving into online learning at about the same pace as the rest of the country, but if anything the college sector is going backwards in terms of enrolments, mainly due to the dramatic drop in enrolments in Cégep à distance in the last two or three years. However there are signs that some of the regular CEGEPs are moving to fill this gap.

Lastly, the results indicated greater use of OER in British Columbia and Ontario and open textbooks in British Columbia. The results also raise the question as to what Québec's strategy should be for OER. Given that French is a minority language and therefore there is likely to be a shortage of francophone OER, should Québec try to be an international leader in the development of francophone open educational resources or is this not where Québec's focus in online learning needs to be? Are there greater priorities?

These are all questions that more and better data could help answer.

\section{Conclusions}

\section{Overall success}

The survey achieved its main objectives: 
i. Sufficient funding was raised to enable the survey to be successfully completed and disseminated.

ii. There was a very good response rate (almost $70 \%$ of the institutional population base and $78 \%$ of all students), considering participation in the survey was voluntary.

iii. The survey was able to indicate accurately the rate of growth in online learning between 2011 and 2016.

iv. By triangulating the results of this national survey with other surveys, it was possible to provide an estimate of the proportion of enrolments that are now fully online.

v. The importance of online learning for the future of Canadian post-secondary education has been clearly established.

vi. The impact of government policies in supporting online learning was measured.

However, the survey also identified some weaknesses in institutional and government policies.

The need to focus on the student and instructor experience

This was a survey of institutions. It does not reflect the views or experience of online learning of either instructors or students. This gap also needs to be filled.

\section{A lack of internal accountability for tracking online learning}

Far too many institutions covered by the survey were not systematically tracking developments in online learning. Some were simply unable (or unwilling) to provide any figures regarding online enrolments. Others provided data but added in the open-ended comments that these were estimates or were of dubious reliability. Different institutions reported enrolment data in different ways, even though the survey provided strong guidance on how to report online enrolments.

As a result it was not possible from the survey alone to provide an accurate estimate of the proportion of teaching that is online in Canadian post-secondary institutions, which was a big disappointment, as this was one of the main goals of the survey.

However, a significant number of institutions were able to provide consistent data over the 5 year period from 2011 to 2016 which indicated growth in online learning within individual institutions, even if the methodology for counting differed between institutions.

This made it possible to triangulate online student enrolment data from the survey with results from other surveys and data collected by:

- the Canadian Virtual University (2015)

- Conseil Superieur de l'Education, Québec (2015)

- Ontario Ministry of Training, Colleges and Universities (2011)

- Global Affairs/Educonsillium, (Martel, 2015).

As a result of this comparison of results from different studies, the national survey project estimated that in 2015 fully online enrolments constituted approximately 16\% 
of all course enrolments in Canadian universities, and $12 \%$ of all course enrolments in colleges outside Québec.

The difficulty many institutions had in providing accurate online enrolment data though is worrying. Over two thirds of the institutions reported that online learning was very or extremely important for their future. However, it is difficult to see how institutions can manage their future if they do not have a good handle on how many students are taking online courses or what proportion of the teaching is now fully online, or how digital technologies are affecting classroom-based teaching.

A more systematic effort needs to be made by institutions and provincial governments to collect reliable and comprehensive data on student online course enrolments on a regular basis in future years, both for fully online and for hybrid courses where classroom teaching is reduced, but not eliminated, to accommodate more online learning.

\section{A recommended methodology}

The report from the national survey discusses the methodological issues in collecting reliable and consistent data on online enrolments and makes a recommendation for how best this can be done. In particular it suggests the following methodology:

i. Identification of the number of students (headcount - full-time and part-time) in the fall semester taking at least one fully online course for credit.

ii. Compare this number with total student headcount (full-time and part-time) taking credit courses in the fall semester, to identify the percentage of students taking at least one online course.

iii. Count over the whole academic year the total of enrolments in each fully online course offered for credit based on a three credit course; for six credit courses double the enrolment number.

iv. Compare this number with the total of enrolments in all types of teaching for credit over the whole academic year, to identify the proportion of teaching that is being done fully online. Ideally this process could be repeated for non-credit courses and programs as well, but as a separate count.

v. Track the number of courses, and the student enrolments, for courses that have reduced but not eliminated face-to-face teaching time replaced by time for online learning; compare this with the total number of courses and student enrolments for all types of teaching.

\section{Future directions}

For this to happen, though, provincial governments and institutions will need to:

- define and agree upon the best way to measure online learning activity,

- identify what data need to be systematically collected,

- establish mechanisms for collecting and reporting consistently on online learning activities, including responsibilities for data collection,

- make available the resources needed to provide such information. 
This is not an impossible task. In most cases, the basic infrastructure is in place, in the form of student information systems and planning and institutional research departments. It will be important to engage organizations such as the Canadian Institutional Research and Planning Association/Association Canadienne de Planification et de Recherché Institutionelles (CIRPA/ACPRI) in determining the methodology for data collection. Collecting the necessary data is more a question of priorities and delegation of responsibility.

However, the most important consideration is that all institutions as far as possible follow the same method in collecting data on online course enrolments in future surveys. This means that not only should this survey be conducted on a regular basis, but that it needs to be embedded in a sustainable, cross-provincial organizational structure with a wider remit to track digital learning developments in Canadian post-secondary education.

\section{Acknowledgements}

As well as the contributions of the members of the research team and sponsors/funders, special thanks are due to the following organizations that provided support for or endorsement of the project:

- Colleges and Institutes Canada (CICAN),

- Colleges Ontario,

- The Canadian Institutional Research and Planning Association (CIRPA),

- The Council of Ontario Universities,

- Universities Canada,

- The Canadian Virtual University,

- Réseau des Cégeps et des Collèges Francophones du Canada (RCCFC),

- Association des Collèges et Universités de la Francophonie Canadienne (ACUFC),

- Réseau d'Enseignement Francophone à Distance du Canada (REFAD).

Funding

The following organizations and agencies provided $C \$ 165,000$ funding for the survey:

- eCampusOntario: $\$ 90,000$ (public-sector not-for-profit)

- Contact North: $\$ 10,000$ ((public-sector not-for-profit)

- Campus Manitoba, \$10,000 (public-sector not-for-profit)

- eCampusAlberta: $\$ 10,000$ (public-sector not-for-profit)

- BCcampus: $\$ 5,000$ (public-sector not-for-profit)

- Pearson Canada: $\$ 20,000$ (private sector, for-profit)

- D2L: $\$ 20,000$ (private sector, for-profit)

\section{Availability of data and materials}

The public report, the full technical report, the main tables and a list of the institutions in the survey universe are available for free downloading from the following websites:

English language: https://onlinelearningsurveycanada.ca/

French language: https://formationenlignecanada.ca/

The institutional database developed for the survey, with names of institutions omitted for privacy reasons, and the raw data from the questionnaire, are lodged with the Ontario College Application Service (OCAS) [https://

www.ontariocolleges.ca/en], and are available to bona fide researchers on request.

\section{Authors' contributions}

The article is solely authored by Dr. TB, the research team lead, with the written agreement and support of the whole research team, who contributed heavily to the conduct of the research itself: Jeff Seaman, Babson Survey Research Group, USA; Russ Poulin, WCET, USA; Ross Paul; Brian Desbiens; Denis Mayer; Eric Martel; Tricia Donovan. The author read and approved the final manuscript.

\section{Author's information}

Dr. Tony Bates is a Research Associate of Contact North, a Distinguished Visiting Professor at the G. Raymond Chang School of Continuing Education, Ryerson University, Toronto, and CEO of Tony Bates Associates Ltd., a private consulting company specializing in online and distance education.

\section{Competing interests}

The author is a distinguished visiting professor at Ryerson University, which was also responsible for administering an $\$ 80,000$ grant to the project. Ryerson University was one of the 203 institutions surveyed. There are no other competing interests of which I am aware. See above for list of organizations that funded the research. 


\section{Publisher's Note}

Springer Nature remains neutral with regard to jurisdictional claims in published maps and institutional affiliations.

Received: 27 February 2018 Accepted: 11 May 2018

Published online: 30 July 2018

\section{References}

Allen, I. E., \& Seaman, J. (2013). Changing course: Ten years of tracking online education in the United States. Wellesley: Babson College/Quahog Research Group http://www.onlinelearningsurvey.com/reports/changingcourse.pdf.

Allen, I. E., \& Seaman, J. (2017). Digital learning compass: Distance education enrollment report 2017. Wellesley: Babson College/eLiterate/WCET

Bates, T., et al. (2017). Tracking online and distance education in Canadian universities and colleges: 2017. Vancouver: The National Survey of Online and Distance Learning in Canadian Post-Secondary Education https:// onlinelearningsurveycanada.ca/.

Canadian Virtual University (2015). E-registrations report 2000/2001-2014/2015. Athabasca: Athabasca University.

Conseil Superieur de l'Education, Québec (2015). La formation à distance dans les universités québécoises: un potentiel à optimizer. Québec City: Gouvernement du Québec.

Contact North (2015). An overview of online learning in Canada. Sudbury ON: Contact North https://contactnorth.ca/ sites/default/files/pdf/external-presentations/an_overview_of_online_learning_in_canada.pdf.

Martel, C. (2015). Online and distance education capacity of Canadian universities. Montreal: EduConsillium.

Ontario (2011). Fact sheet summary of Ontario elearning surveys of publicly assisted PSE institutions. Toronto: Ministry of Training, Colleges and Universities.

Seaman, J. E., Allen, I. E., \& Seaman, J. (2018). Grade increase: Tracking distance education in the United States. Wellesley: The Babson Survey Research Group.

Submit your manuscript to a SpringerOpen ${ }^{\circ}$ journal and benefit from:

- Convenient online submission

- Rigorous peer review

- Open access: articles freely available online

- High visibility within the field

Retaining the copyright to your article

Submit your next manuscript at $>$ springeropen.com 